\section{HYDATIDOSIS IN A LION}

\section{V.M. Dhoot ${ }^{1}$ and S.V. Upadhye ${ }^{2}$}

${ }^{1}$ Officer In-charge, Maharajbag Zoo, ${ }^{2}$ Assistant Professor, Veterinary Science, College of Agriculture, Nagpur, Maharasthra, India

Echinococcus granulosus is a parasite in dogs, wolves and rarely occurs in other carnivores. The eggs are ingested by wild and domestic herbivores where they hatch. The oncospheres invade the circulatory system and lodge in various parts of the body especially in the liver and lungs. They develop into large cysts (hydatids) that bud scolices endogenously (Anonymous, 1986). Reports on hydatidosis in wild animals is scarce. The present paper reports a case of hydatidosis in a lion.

A 22-year-old lion belonging to Maharajbag Zoo, died after showing signs of illness for about 10 days. Cysts recovered from the lungs of the lion were examined to identify the parasite.

On postmortem examination, congestion of conjunctiva, heart, lungs, kidneys and engorged sub-cutaneous blood vessels were observed. The liver was severely congested with large number of hydatid cysts (from a size of a lemon drop to tennis ball). Stomach showed mucosal erosions and the intestinal blood vessels were engorged. Blood smear did not reveal any infection. The cysts contained large amount of fluid and protoscolices that showed vigorous movement of sucker and rostellum. The metacestode stage was identified to be hydatid cyst due to Echinococcus granulosus. Death was confirmed to be due to liver dysfunction caused by hydatid cysts. Hydatidosis in animals and man is an important disease. In definitive host, the adult worm does not cause so much distress, but metacestode stage of the parasite in intermediate host is responsible for dysfunction of vital organs due to pressure atrophy. The cyst lodgment causes interference with the function of the affected organs with the danger of even fatality in certain cases (Bhattacharya et al., 2000)

Echinococcus granulosus is perpetuated primarily in domestic cycle involving dog as the definitive host and livestock like buffalo, cattle, sheep, goat and pig and transport animals like donkey, horse, camel and yak as its intermediate host (Verma et al., 1998). Hydatidosis has been reported in wild herbivores such as American Bison (Choudhary et al., 1987), Swamp Deer (Verma et al., 1994) and Ladakhi Goat (Chakraborty, 1999). Rao et al. (1973) reported E. granulosus in an Indian Wolf. Lungs and liver were the organs mostly affected. Verma et al. (1994) opined that the Swamp Deer might act as natural definitive or reservoir host for hydatidosis which might be a case of sylvatic cycle prevalent between cervids and canine or feline hosts.

Singh and Banarjee (1997) also opined that apart from the strains of $E$. granulosus involving domestic animals, other strains exist with sylvatic cycles and these include Moose/Wolf in North America, Wallaby/Dingo in Australia, Deer/Jackal in Sri Lanka, Deer/Coyote in California, Hare/Fox in Argentina, Elk/Wolf or Elk/Dog in erstwhile USSR and wild ungulates/Lim, Cape Hunting Dog, Jackal in southern Kenya.

In the present case, the lion died after illness of about 10 days and necropsy revealed liver dysfunction due to large number of hydatid cysts of varying sizes. However, the exact route of acquiring the infection of $E$. granulosus by the lion could not be ascertained.

\section{References}

Anonymous (1986). CNS diseases caused by Helminths and insect larvae. Hydatid disease, pp. 572-73. In: Merck Veterinary Manual, $6^{\text {th }}$ edition. Published by Merck Co. Inc., Rahway, NJ, USA,

Bhattacharya, D., S.C. Das and A. Sikdar (2000). Control of hydatidosis in man: veterinarian's may play pivotal role. Intas Polyvet 1(1): 84-85.

Chakraborty, A. (1999). Mortality in different species of animals of Assam State Zoo, Guwahati. In: Proceeding workshop on health and management of zoo animals for zoo veterinarians, held at Guwahati, 28-30, October 1999.

Choudhary, C., B. Narasimhaswamy, V. Shivashankar, M.R.K. Rao and J.H. Das (1987). Hydatidosis in lungs and liver of an American Bison (Bison bison). Indian Veterinary Journal 64(8): 713-714.

Rao A.T., B.C. Nayak and L.N. Acharjyo (1973). Histopathology of intestinal lesions due to E. granulosis in an Indian Wolf. Indian Veterinary Journal 50: 199-200.

Singh, S. and D.P. Banerjee (1997). Role of wildlife in parasitic diseases of man and animals. Zoo's Print 12(4): 14-16.

Verma T.K., H.C. Malviya and B.M. Arora (1994). Hydatid cyst from a Swamp Deer (Cervus duvauceli duvauceli). Journal of Veterinary Parasitology 8(2): 99-100.

Verma T.K., A. Prasad and B.M. Arora (1998). Morphology, transmission and experimental studies on Echinococcus granulosus isolated from giant squirrel. Indian Journal of Veterinary Research 7(1): 18-24. 